\title{
A review of silk ageing: mechanism and stimulation methods
}

\begin{abstract}
Historical textile relics are the treasure of human yet suffered from serious ageing. The unearthed ancient textile products are being deformed and even beyond recognition. In order to preserve and understand the historical context of them, artificial ageing of silk textile is important as it provides artificial ageing experimental samples and help to explore the possible reasons for the degradation of ancient textiles. Hence, the particularity of silk and the threatening factors are introduced, mechanisms of ageing, includes physical, photochemical, thermal, chemical, mechanical and biological, are reviewed and the methods of stimulating the degradation, includes photochemical, thermal, hydrolytic and mechanical stress, are investigated.
\end{abstract}

Volume 5 Issue 4 - 2020

\author{
Mei Yu Yao, Tao Liu, Li LI \\ Institute of Textiles and Clothing, Hong Kong Polytechnic \\ University, Hong Kong
}

Correspondence: Li LI, Institute of Textiles and Clothing, The Hong Kong Polytechnic University, Hong Kong, Email li.lily@polyu.edu.hk

Received: July 25, 2020 | Published: August 20, 2020

Keywords: silk, degradation, artificial ageing, conversation, textile relics

\section{Introduction}

Textile relics are perishable materials that become extremely fragile and decay rapidly after excavation. The cost of maintenance to simulate ideal conditions for the relics is exceedingly high and current technology may not support prompt preservation. Still, research indicates the surrounding environment of cultural relics has a great impact on their long-term preservation. ${ }^{1}$ Different textile materials require different care and handling methods. Take silk as an example. The fibers come from typical Chinese Bombyx mori silkworm cocoons. Their protein composition and amorphous structure dictates the properties of high strength, a sturdy resistance to chemicals and microorganisms, and low elasticity and extensibility. Nevertheless, due to poorly ordered amorphous regions and rich in reactive residues, easy deterioration is resulted through water, light, heat, and microorganisms. ${ }^{2,3}$ Another example can be found in the ageing of wool products. It is a natural composite material, comprised of keratin as the major component. Cysteine residues in the keratin are oxidized to provide inter- and intra-molecular disulfide bonds. ${ }^{4,5}$ This contributes to high stability and low solubility with easy deterioration due to acid, alkali, water, light, heat, mineral salts, and microorganisms. ${ }^{6}$ What makes the case more sophisticated is the application of other materials on the design of the ancient textile products. For instance, gold thread was employed for decorative embroidery. Different materials required different handling and conditions for conservation. Although previous research indicates the optimal environment for preserving historical relics, ${ }^{7,8}$ it neglects the complexity of different textiles and the decorative materials used. Therefore, due to the particularity of the textile relics, conversation of unearthed relics is extremely difficult. This study will thus identify the particularity of silk and factors affecting it, and discuss its degradation mechanism. By understanding its properties and ageing mechanism, it hopes to help with developing a suitable handling environment for conversation and exploring the possible reasons for the degradation of ancient textiles in the future. Then, a review on current artificial ageing methods will be done in order to provide insights for conversation of the precious silk relics. Those methods help to provide artificial ageing experimental samples and benefit archeology.

\section{Particularity of silk and factors threatening sillk products}

Ancient Chinese textile relics were mainly woven from silk, which has valuable properties such as high lustre, good handle, high strength and light in weight. Silk is a natural protein fiber, which mainly containing about $72 \%-81 \%$ silk fibroin, about $19 \%-28 \%$ sericin, and about $3 \%$ of other substances such as wax substances, sugar substances, pigments, and inorganic substances and so on. ${ }^{9}$ Its structure is shown on Figure 1. Both silk fibroin and sericin are proteins, and they have a polypeptide chain structure composed of amino acids. Since sericin is amorphous in nature that assists the structural integrity of the cocoon, it is more water-soluble when compared to fibroin and easier to be affected by external factors. ${ }^{10}$ Therefore the denaturation of sericin protein has a great influence on the properties of silk. In addition, although high crystallinity of silk contributes to its great strength, ${ }^{11}$ it loses almost $20 \%$ of its strength when it gets wet. Pérez-Rigueiro et al. ${ }^{12}$ reported that immersion in water causes weakening of hydrogen bonds of silk and thus adversely affect its mechanical properties. It can also be stretched with slightly elongation. Its shrinkage rate is about $4-8 \%$. Its structure can be affected by sunlight, insects and sulfuric acid. ${ }^{13}$ Hence thanks to these properties, silk is sensitive to environmental degradation and easily damaged, especially silk relics are facing extremely hard conditions.

Previous researches have been done on analyzing the factor threatening of silk cultural relics. Generally, degradation is triggered by physical, chemical, and biological factors. ${ }^{7}$ Regarding physical factor, it is related to the origin, size, and shape of the object itself. For example, low relative humidity causes some materials like wood to become more sensitive to mechanical stress, while environmental humidity fluctuations provide stress that may eventually weaken the structure of the relics. For chemical factor, various elements like oxygen, nitrogen, water, carbon dioxide, and sulfur dioxide may cause degradation via redox reactions, depolymerization, hydrolysis, etc. For biological factor, it is related to the growth of microorganisms. It usually occurs in polluted environments with high relative humidity, high temperature, poor ventilation, and strong light sources. The 
favourable temperature for bacteria proliferation is $25^{\circ} \mathrm{C}$ to $42^{\circ} \mathrm{C}$ in general. When the temperature and humidity are appropriate, the bacteria will multiply, and the textile relics will be damaged or destroyed. However, the degradation of silk relics tends to be even more complicated due to different weaving methods, historical times, and environment.

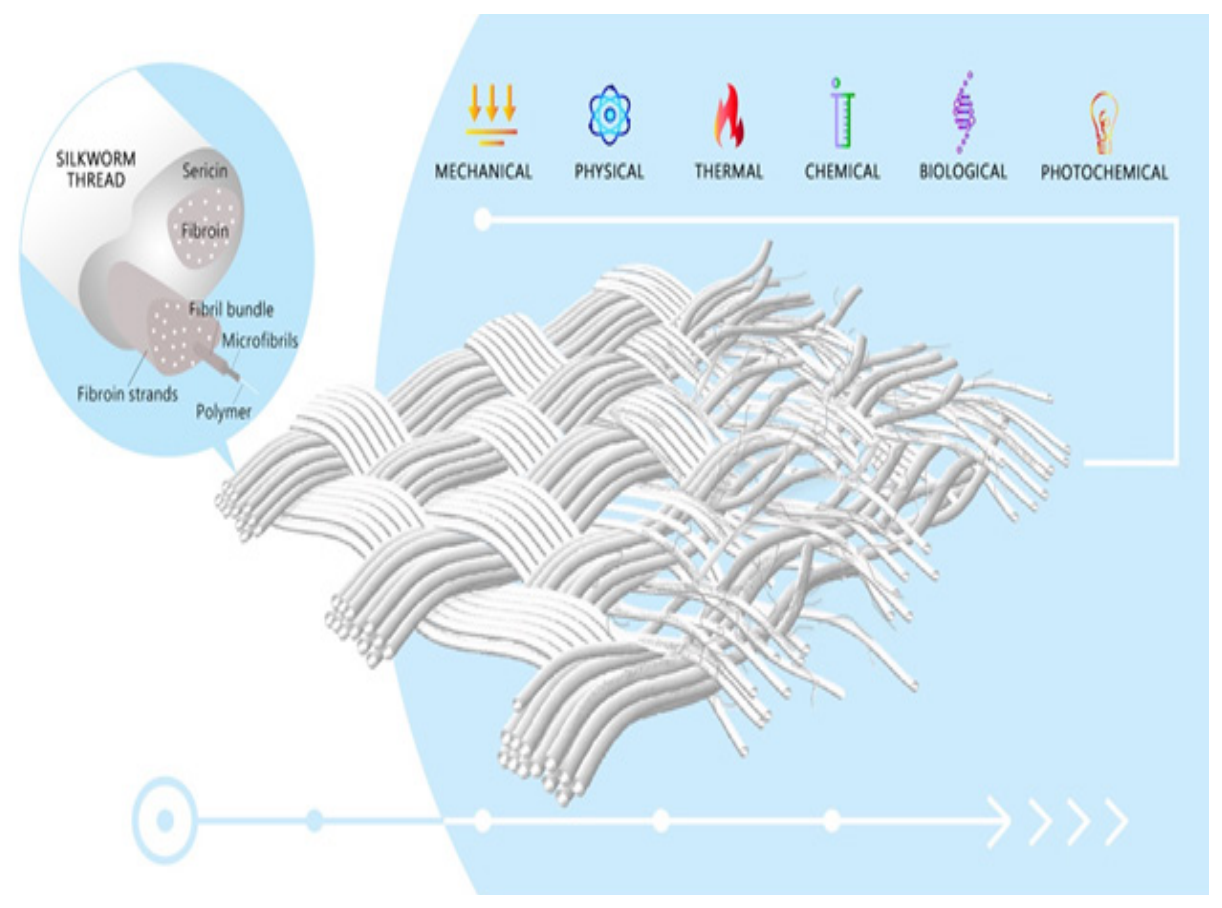

Figure I Figure showing the structure of a silk fiber and the mechanism of ageing.

In additions, there are many factors that cause damage to silk cultural relics. For instance, natural disaster and human error are other important factors. ${ }^{14}$ Natural disasters, like earthquakes and associated hazards, or fires, pose harmful damage to the relics. This is difficult to avoid as some museums and heritages are located near the earthquake zone. An earthquake occurred at Sichuan in 2008 and damaged over 600 relics, including 4 first-grade cultural relics (according to Chinese relic standard), and 16 museums, such as Wudu District Museum, all of which became dangerous buildings. ${ }^{15}$ Human factors include physical forces, criminals, contaminants, etc. ${ }^{14}$ Most of the time, the damage takes place from subtle daily handling of the relics. For instance, when a relic is going to be exhibited at a museum, moving and transporting is necessary. Even slight vibration may cause irreversible damage to the relic.

\section{Ageing mechanism of sillk}

Ageing refers to the phenomenon that the mechanical properties of the polymer deteriorate due to physical and chemical factors. The main reaction in the ageing process is degradation, while sometimes accompanied by a cross-linking reaction. Degradation of polymers includes chemical processes such as depolymerization, random cleavage, and removal of side groups or low molecular weight substances. ${ }^{16}$ Previous researches suggested that mechanism of ageing is physical, photochemical, thermal, chemical, mechanical and biological. ${ }^{17,18}$ It is believed that all the factors are complex and changeable, and they affect each other at the same time.

Regarding physical mechanism of ageing, it is mainly manifested as the increase in density and hardness of polymer fibers during longterm storage. Bresee ${ }^{17}$ believed that silk fiber is in rod-shaped which has a huge specific surface area. Since most of the polymer fibers contain non-crystalline regions and their glass transition temperature is higher than room temperature, therefore physical ageing will be occurred during at room temperature. It is believed that serine and tyrosine contain active groups that are prone to oxidation, and this is the main reason for the depreciation in the fiber property. ${ }^{19}$ In addition, metal ions in the soil are another reason for degrading the performance of the fabric. Generally, the ageing time can be predicted by calculation since the physical ageing has a strong regularity. The time range varies from a few minutes to hundreds of years. It can be seen from the molecular structure of amino acids that serine, tyrosine, and phenylalanine are prone to oxidation reactions because of their active groups. ${ }^{20}$ It leads to the denaturation of silk fibroin. As a result, it has been proposed to judge the degree of deterioration by observing changes in serine, tyrosine, and phenylalanine.

For the photochemical mechanism of ageing, silk fiber is also very sensitive to light that UV exposure may lead hydrogen bonds broke and the silk fibroin oxidized. When silk is exposed to light for a long time, the silk protein molecules are denatured which can cause silk fibers beginning to yellow and breaking easily. ${ }^{21}$ It is believed silk fibroin macromolecules are prone to photo-oxidative degradation or photochemical effects under the illumination of xenon lamps or ultraviolet rays. Silk fiber contains high molecular polymer. When the energy of light equals or exceeds the energy of the intermolecular hydrogen bond, and the covalent bond between atoms, the protein molecules will be denatured and broken. It is more prone to the photosensitive reaction when there is a tertiary carbon on the peptide chain. Free radicals are generated and cause the dissociation of the chain. The strength of the silk fabric is therefore obviously reduced, discolored, and brittle. Ultraviolet radiation not only affects the molecular structure of silk protein but also the dyes of silk fabrics, as 
light energy may change the molecular structure of dyes. Concerning the thermal ageing of silk, it can physically and chemically reduce the performance of silk fabrics. ${ }^{22}$ When the temperature is higher than the glass transition state of the polymer material, the degree of molecular orientation will be changed and make the relative movement of the molecular chain easier. Therefore, it is easier for other molecules to penetrate the fiber to undergo chemical reactions and cause corrosion.

Chemical ageing is another major mechanism. Although silk is resistant to most mineral acids, it is still susceptible to multitude of chemical species' attack. Chemical diversity of molecules trigger reactivity and is increased with degradation. That means chemical attack enhanced with higher level of degradation. Silk as protein fiber is thus more susceptible to chemical attack. In addition, chemical attack and crystallinity is inversely correlated. ${ }^{17}$ Mechanical ageing occurred due to the deformation of silk cultural relics under the longterm landfill environment. ${ }^{17}$ The distortion and deformation of the molecular chain of the fiber lead to the breakage of the molecular chain and thus make changes in size, shape, and mechanical properties. Besides, the process of unfolding may cause polymer chain scission and result is the size and shape of the fiber would change or cause silk fiber rupture. Biological degradation occurred when the silk fabrics are buried in the soil. The microorganisms will decrease the fabric's mechanical properties and increase its' ageing extent. Ishiguro et al. ${ }^{18}$ studied the effect of bio-corrosion on silk fabrics through soil landfill experiments and believed that bio-corrosion is not avoidable when compared to chemical degradation.

\section{Methods of stimulating silk relics}

Silk fiber can be artificially ageing by difference methods. The purposes of artificial ageing are to provide artificial ageing experimental samples and to explore the possible reasons for the degradation of ancient textiles. The stimulating methods are photochemical, thermal, hydrolytic and mechanical stress degradation. Photochemical degradation is a method of passing silk fabrics through light to cause the degradation process. The tools currently used are mainly xenon lamps or ultraviolet lamps. A full-spectrum xenon arc lamp is used to simulate the destructive light waves in sunlight, including UV, visible light, and infrared light. At present, a wavelength of $254 \mathrm{~nm}$ and $365 \mathrm{~nm}$ ultraviolet rays is commonly used to degrade modern silk. ${ }^{23,24}$ It can be accurately and efficiently simulated the light ageing degree of ancient silk fabrics in various ages by controlling the ageing time and intensity.

There are two types of thermal degradation, one is the change of physical properties, and the other involves a chemical reaction. ${ }^{17,22}$ Usually, the silk is heated and baked in a blast convection oven. In the heating process, it is often sprayed with distilled water to achieve the degrading effect. After heat treatment, the silk fiber loses weight and begins to turn yellow. Shrinkage streaks appear on the fiber surface. Its breaking strength and elongation also decrease. According to Nilsson et al. ${ }^{25}$ study, thermo-oxidation condition can stimulate the ageing situation of silk, and eventually change physical and chemical properties of silk fiber. Hydrolytic degradation requires the samples to be immersed in distilled water, aqueous $\mathrm{NaOH}$ or dilute hydrochloric acid. The modern silk fiber is artificially aged by simulating the ageing environment of ancient silk fabrics and using acid and alkali solutions as media. Studies have shown that silk fibers lose weight after treatment with deionized water, tap water, acid and alkali solutions. The weight loss rate is enhanced with the processing time and the increase of acidity and alkalinity. ${ }^{26}$ The internal structure of silk fiber becomes loose after hydrolysis, which is very similar to the unearthed silk fabric.

Mechanical stress degradation refers to the burial of modern silk fabrics under artificial conditions similar to archaeological environments, even if they are in a humid environment. After the degradation, the silk fabric loses weight and turns yellow. Given enough degrading time, the silk fiber suffers severe corrosion and peeling. Some researchers buried silk fiber in the soil to study its biodegradability, and found that there are many traces of soil microbial erosion on the surface of the fiber. At the same time, some microorganisms and soil particles were also found to remain inside the fibers. The results showed that the silk fiber was damaged by erosion and cause micropores inside. In addition, soils in different regions have different effects on the structure and performance of silk fibers. ${ }^{18}$ Therefore, the use of mechanical stress ageing must focus on the similarity of the unearthed cultural relic environment.

\section{Conclusion}

Doubtlessly, historical relics have high historical value, and exemplified the wisdom, cultural formation, and technological development over thousands of years. It is also recognized as a source of valuable wealth for human consumption. ${ }^{27}$ Unfortunately, due to the particularity of silk and various threatening factors, unearthed silk is extremely fragile and seriously damaged. The mechanism of ageing is physical, photochemical, thermal, chemical, mechanical and biological. By understanding that mechanism, stimulation of degradation can be done to reveal the mystery of textile relics. This paper reviews four major degradation methods. They are photochemical, thermal, hydrolytic and mechanical stress degradation. It can stimulate the ageing time, which means it help to find the historical context in the relics and what happened. This not just benefits textile study, but also archaeology.

\section{Acknowledgments}

Special thank is made to General Research Fund for funding and supporting this project.

\section{Funding}

This research project is funded by General Research Fund -- Hong Kong Research Grants Council. The project title is "Development of an Innovative, Flexible Smart Monitoring System for the Conversation of Textile Relics" and the reference number is 15600919 .

\section{Conflicts of interest}

There is no conflict of interest.

\section{References}

1. Camuffo D. Microclimate for cultural heritage: conservation, restoration, and maintenance of indoor and outdoor monuments. Elsevier. 2013.

2. Garside P, Wyeth P. Crystallinity and degradation of silk: correlations between analytical signatures and physical condition on ageing. Applied Physics A. 2007;89(4):871-876.

3. Zhang X, Berghe IV, Wyeth P. Heat and moisture promoted deterioration of raw silk estimated by amino acid analysis. Journal of Cultural Heritage. 2011;12(4):408-411.

4. Lin $\mathrm{Z}, \mathrm{Yu} \mathrm{N}$, Zhou $\mathrm{Y}$, et al. The aging effect of $\mathrm{CaCl} 2$ and $\mathrm{NaCl}$ on wool fabrics with hydrothermal treatment. Textile Research Journal. 2017;87(4):399-408. 
5. Cardamone JM. Investigating the microstructure of keratin extracted from wool: Peptide sequence (MALDI-TOF/TOF) and protein conformation (FTIR). Journal of molecular structure. 2010;969(1-3):97-105.

6. Ghosh A, Grosvenor AJ, Dyer JM. Improving the properties of chemically damaged wool fabrics with carbohydrate polymers. Journal of Applied Polymer Science. 2013;130(5):3105-3111.

7. Cannistraro G, Cannistraro M, Restivo R. Thermo Hygrometric Monitoring Using Wireless Sensors: Study of Seventeenth-Century Church's Microclimatic Conditions and Enclosed Reliquary. Science Series Data Report. 2012;4(4):101-123.

8. Ping Z, Chen ZL, Wei X. Utilization Model of Underground Space to Protect Historical Relics. 11th ACUUS Conference: "Underground Space: Expanding the Frontiers”, Greece: Athens; 2007.

9. Soochow University. Zhi Si Huaxue. China Textile \& Apparel Press; 1979.

10. Chopra S, Gulrajani ML. Comparative evaluation of the various methods of degumming silk. Indian Journal of Fibre \& Textile Research. 1994;19:76-83.

11. Sutherland TD, Young JH, Weisman S, et al. Insect silk: one name, many materials. Annual review of entomology. 2010;55:171-188.

12. Perez-Rigueiro J, Viney C, Llorca $\mathrm{J}$, et al. Mechanical properties of silkworm silk in liquid media. Polymer. 2000;41(23):8433-8439.

13. Silk. 2020.

14. Sperantza C, Papadimitriou M, Pournou A. Risk management: a case study of the wooden collection held in storage at the Folk Art Museum of Athens, Greece. Proceedings from International Conference on Wooden Cultural Heritage: Evaluation of Deterioration and Management of Change. 2009.

15. $\mathrm{Su} \mathrm{XD} .607$ pieces of cultural relics in Gansu were damaged in the earthquake 16 Museums Become Dangerous. Lanzhou Chenbao. 2008.

16. Shi CL, Zhang FW, Chen ZW. Scanning Electron Microscopic Observation on Mlo in Freeze-Fractured Phloem Tissues of Witche'S-Broom Diseased Jujube. Acta Microbiologica Sinica. 1984;1984(2):43-45.
17. Bresee RR. General effects of ageing on textiles. Journal of the American Institute for Conservation. 1986;25(1):39-48.

18. Ishiguro Y, Zhou Y, Tajima F. Analysis of biodegradability of silk threads embedded in soil using image processing[J]. Proceedings. Proceedings of the 4th international Silk Conference, State Bureau of Textile Industries, People's Republic of China. 2000;109-114.

19. Miller JE, Reagan BM. Degradation in Weighted and Unweighted Historic Silks. Journal of the American Institute for Conservation. 1989;28(2):97.

20. Sionkowska A, Planecka A. The influence of UV radiation on silk fibroin. Polymer Degradation and Stability. 2011;96(4):523-528.

21. Liu H, Zhao S, Zhang Q, et al. Secondary structure transformation and mechanical properties of silk fibers by ultraviolet irradiation and water. Textile Research Journal. 2019;89(14):2802-2812.

22. Vilaplana F, Nilsson J, Sommer DV, et al. Analytical markers for silk degradation: comparing historic silk and silk artificially aged in different environments. Analytical and bioanalytical chemistry. 2015;407(5):1433-1449.

23. Hirabayashi K, Yanagi Y, Kawakami S, et al. Degradation of silk fibroin. The Journal of Sericultural Science of Japan. 1987;56(1):18-22.

24. Zhang XM, Yuan SX. Analytical research on the amino acids of aging silk. Sciences of Conservation and Archaeology. 2003;15(4):18-26.

25. Nilsson J, Vilaplana F, Karlsson S, et al. The validation of artificial ageing methods for silk textiles using markers for chemical and physical properties of seventeenth-century silk. Studies in conservation. 2010;55(1):55-65.

26. Wang YL, Zhao F. Experimental investigation on artificial aging hydrolysis of silk. Journal of Silk. 2006(11):49-57.

27. Lu D, Pan Y. Digital preservation for heritages: technologies and applications. Springer Science \& Business Media; 2011. 